\title{
Drivers and Self Ego States in Social Cognitive TA: a research on drivers as protective strategies
}

\author{
(C) 2012 Laura Bastianelli TSTA-Psychotherapy, Davide Ceridono PTSTA- \\ Psychotherapy
}

\begin{abstract}
The work presents a synthesis of a set of studies of a correlational research conducted by Scilligo and coworkers on drivers and their relationship with the developmental Self-integration. Drivers are examined in the light of their historical development in TA. A definition is adopted that sees the drivers as normative protective strategies that can acquire dysfunctional connotations both when they are absent and when they are present in a rigid and "out of context" way. Selfintegration is defined in term of self-perception of Self Ego state according to Social Cognitive TA. Subjects ( $N=$ 700) were adults, mostly university students and trainees in clinical psychology. The five drivers (Hurry Up, Please Me, Try Hard, Be Strong, Be Perfect) were measured with the Espero self-report questionnaire (Scilligo, 2005) and Self Ego States were measured with the Anint self-report questionnaire based on SASB (Benjamin, 1974, 2000; Scilligo \& Benjamin, 1993, Scilligo 2005) by which 12 prototypical Ego states are operationally defined according to SCTA (Scilligo, 2009; De Luca e Tosi, 2011).
\end{abstract}

Different studies were conducted for men and women, concerning Ego states for three levels of each of the five drivers. Results show, for all the drivers, that an average level of the driver is related with Self Ego State profiles indicating good integration both for men and women. High level of the driver is related with less integration of Self, except for Be Strong and Be Perfect in men, which result is associated to a functional profile of Ego states. Low level of the drivers is related to less integration of Ego states except for Be Strong in women, and for Hurry Up both for men and women. Results support the hypothesis of a non-linear relationship between drivers and Self-integration, with better levels of integration in subjects with average levels of drivers.

\section{Introduction}

Over the years the concept of counterinjunction has assumed a certain importance in Transactional Analysis. Berne (1970) wrote "Man is born free, but one of the first things he learns is to do as he is told, and he spends the rest of his life doing that. Thus his first enslavement is to his parents. He follows their instructions forevermore, retaining only in some cases the right to choose his own methods and consoling himself with an illusion of autonomy' (p. 177).

Berne often seems to consider the individuation process as a courageous exception and not as a natural process as claimed by several developmental theories. In his mind there was the idea of a dominant self-limiting adaptation rather than of an adaptation allowing the growth of the child: he did not always recognize the ability of the child to influence the parents and the surrounding environment. In his view, the person is seen as tending to perpetuate dependency, and almost all the power of psychological development comes from parents and goes to the child, who has a limited range of choices and is shaped by these external forces. In contrast with this, elsewhere he talks of autonomous individuals as under the influence of Physis in the sense of a "general creative force" (Berne, 1968). In his theory, counterinjunctions are verbal and culturally well accepted messages, given with good intentions but reinforcing the script, thus limiting autonomy.

Kahler (1974) developed the concept of miniscript to describe the very short behavioural sequences through which people carry out their script. The process sequence from which the event script begins is called "drive" and not counterinjunction to show how each person performs regular behaviours associated with a specific drive linked to internal dynamics. Focus is on the observable behaviour, not on the limiting messages incorporated in the Parent (counterinjunctions). When the individual is under the drive influence, he carries out a grandiose process supported by the illusory idea that if he only sacrifices (his wants and needs) devaluing himself, then he can get love, respect, consideration, and acceptance by the significant other. Then by drives people live and feel seemingly OK, even if conditional, avoiding isolation and the fear of abandonment, but without realizing how this always involves a major sacrifice that hinders their autonomy and independence. 
Kahler outlines five main categories of behaviour or drives which start off not-OK behaviour: Please $\mathrm{Me}, \mathrm{Be}$ Perfect, Try Hard, Hurry Up and Be Strong. Each of them can be easily detected through the observation of some indices with which they occur: verbal expressions, tone of voice, gestures, body postures and characteristic expressions of social events and dysfunctional intrapsychic and relational dynamics.

Goulding \& Goulding (1979) offer a perspective that significantly differs from the theory of Berne and is a turning point in the theory and practice of Transactional Analysis. They promote a vision of man as an active agent, capable to choose through a never-ending creative process, making decisions about himself and his life and structuring himself while searching for a dialectical adaptation.

The Gouldings contrast the vision of the child as passive and under external pressure, first of all by the parents, and propose a new framework of reference in which the child has the power to write his own script, deciding and choosing what to believe and what messages to join; in this perspective, the child begins to plan his life and build his script (including counterinjunctions) on the basis of a primary decision that he takes about himself and he can, in the course of life continue to take additional decisions and broaden his view.

Clarkson (1992), says that sometimes the concept of counterinjunction is misunderstood and misused in practice, with the risk of blocking behaviours by opposing, in fact, the natural tendency for people to grow, develop and break free from the constraints of the script. This happens when the parental messages (which invite you to be strong, perfect, fast, etc.) are connected to the "You Are Ok if...": in this context, the messages become destructive. This distinction is important if you want to avoid saying that there is something wrong in the "autonomous aspirations" (Berne, 1972) to be fast, energetic, strong, able to please and excel.

Being fast, energetic, strong, able to please and excel is not the same as being in driver behaviour. Clarkson also points out that the child can either decide to accept drivers as limitations that affect his feeling OK, or decide to get them as values that support the expression of his personality. In summary, drivers need not to be diagnosed by content, but by a combination of behavioural, physical and psychological indicators, tied to oppressive messages, limiting a full sense of self and opposed to Physis. In her words, "The aspiration to be fast, energetic, pleasing, strong, and excellent are fine goals, profoundly compatible with a value base that places the fulfilment of human potential as a cornerstone of all its efforts, knowledge, practice, epistemology, and ethics" (p. 19).

Hazell (1989) considers drivers as the manifestation of habits used to meet the challenges and stresses of life. Many of these habits are useful when moderated, but counterproductive when they are poorly controlled. He sees the habits related to drivers as positive when they are used to achieve a goal or an objective and negative when used to avoid it. The difference is subtle: it can be a double face of the same coin. Thus, the Kahler "Please $\mathrm{Me}$ " is redefined as "Be nice, or pleasant or nice" and "Be Perfect" as "Be specific," to describe a goal that is desirable and possible to achieve.

Other authors (e.g., Caper and Goodman, 1983) reported that negative drivers behaviours have an immediate survival value, although they may be threatening. Conway (1978) considers drivers as resources for coping: they help us to maintain an illusion of control over our lives. Gellert (1975) believes that drivers have a survival value, all linked to the fundamental self-realization driver. Mescavage and Silver (1977) believe that "Please Me" and "Try Hard" are not to be considered as counterscript drivers, but as "necessary conditions for the acculturation" and as such, they are more generalized and associated with early stages of psychosocial development. Johnson (1997) suggests a conceptual revision of the counterinjunctions model emphasizing the work made by Clarkson (1992).

\section{Scilligo's perspective.}

Scilligo had a conception of the person that is far from deterministic interpretations and took a position similar to that of Goulding \& Goulding (1979) going even further: he gave the person will and orientation towards the future without ignoring genetic and contextual constraints. For Scilligo an individual can be described as "...a web of potential meanings, values, and norms of action with emotional valence, creatively emerging from experience, in view of a core tendency of the person who projects self into the future, in the context of his genetic endowment, as well as the present and past context of his physical, interpersonal, social, and cultural world." (Scilligo, 2009, p. 64) This definition clearly implies the presence of normative aspects deriving from context, including normative aspects called counterinjunctions. From this perspective, counterinjunctions can be due both to messages by important persons and to creative processes to manage and solve the problems of existing, surviving and reproducing. The main point is that people adopt counterinjnctions to protect themselves in ordinary daily contexts, and often automatically apply old decisions even when contexts are changed. Counterinjnctions are useful, and can be seen and defined as protective strategies. They can be observed in specific behaviors, called drivers, the "counterinjunction in action". When drivers are absent if the context requires them for functional well-being or they are present for irrational requirements as pure automatism and decontextualised habit, this can be harmful.

\section{Social-cognitive Transactional Analysis and Ego States model}

In Social-Cognitive Transactional Analysis (SCTA) Ego states are considered especially in their relational aspects that can be observed in intrapsychic and interpersonal processes. 
SCTA explains Ego states (ES) with the concept of schemas: structures of meaning that integrate knowledge.

Ego states are organized by schemas (Scilligo, 2009) that are the bases of representations of self, others, and relationships between self and others.

Social-Cognitive Transactional Analysis (Scilligo, 2009; Ceridono, Gubinelli and Scilligo, 2009; De Luca and Tosi, 2011) has developed operational definitions of the concepts of Ego states and instruments of observation based on Structural Analysis of Social Behavior SASB (Benjamin, 1974, 1996, 2003) that permit empirical research and orientation in clinical work.

Using the two orthogonal dimensions of SASB, Affiliation (Friendly v Hostile affectivity) and Interdependence (Give v Take away power), Ego states can be described in their functional aspect.

The crossing of Affiliation and Interdependence generate four categories of relationships that delineate four types of Ego states: Free, Protective, Critical, and Rebellious. This way of describing the Ego states can be represented as in Figure 1. Hence, every Ego State is characterized by four sub-Ego States:

- Parent Ego State: Free Parent, Protective Parent, Critical Parent and Rebellious Parent;

- $\quad$ Adult Ego State: Free Adult, Protective Adult, Critical Adult and Rebellious Adult;

- Child Ego State: Free Child, Protective Child, Critical Child and Rebellious Child;

The 12 ego States can be put in a circumplex defined by the two dimensions: Affiliation (Friendly $v$ hostile affectivity) and Interdependence (Give $v$ Take away power; see Figure 2).

People with good Self integration should show high levels of Self Ego States related to wellbeing (FA, FC, PA, $P C)$, average levels of FP and PP, low levels of Self Ego States related to pathology (CA, CC, RC, RA) and average-low levels of CP and RP (Scilligo, 2003).

\section{Hypothesis}

On the basis of theory overview on counterinjunctions and drivers the authors investigated the relation between protective strategies (drivers) and selfintegration.

According to the SCTA theory, drivers are normative protective strategies that can acquire dysfunctional connotations both when they are absent and when they are present in a rigid and "out of context" way. The authors formulated the hypothesis that average levels of each driver are associated with Ego State profiles indicating personal integration of Self and well-being, and high or low levels of driver correlate with dysfunctional Ego States profiles.

To test this hypothesis the authors made a correlation research that studied the relationship between drivers and Self Ego State profile.

\section{Method}

\section{Subjects and instruments}

Subjects were adults $(\mathrm{N}=700)$, males $(\mathrm{N}=284)$ and females ( $N=316)$, aged between 25 and 35, mostly students and graduates students in clinical psychology.

Drivers were observed with Espero, a self-report questionnaire (Scilligo, 2005), created to measure 5 drivers and 15 injunctions. The questionnaire is composed by 120 items that are self-descriptions of how the person behaves or perceives the situations. Item examples are: I do what people say, not to seem different. (Please Me); I feel uncomfortable when I do things slowly (Hurry Up); If I start a job I complete it even after hours (Try Hard); It is better to swallow the tears rather than letting them out (Be Strong); You have to let go and be sweet (Be Strong, reversed); You have to do things well or nothing (Be Perfect). Each item consists of a statement that the subject evaluates on a Likert scale with four levels: 1 (false for me), 2 (slightly false for me) 3 (mostly true for me), 4 (true for me). Each driver is measured with a scale composed by 6 items. The score of each scale is the sum of the responses to the items that constitute the scale, and ranges from a minimum of 6 to a maximum of 24. Item analysis (Scilligo, 2005) showed a good Cronbach's Alpha: .73 (Please Me); .77 (Hurry Up); .70 (Be Strong); .77 (Try Hard); .73 (Be Perfect).

Self Ego states were studied with Anint A, a 36 items self-report questionnaire based on Introject surface of Structural Analysis of Social Behavior, SASB (Benjamin, 1974, 2000; Scilligo \& Benjamin, 1993, Scilligo 2005) that we use to measure the operationally defined Ego States, according to Social-Cognitive TA (Scilligo, 2000; Scilligo, 2009; Ceridono, Gubinelli and Scilligo, 2009; De Luca and Tosi, 2011). Anint A has 12 scales to measure the 12 prototypical Self Ego states, also called Developmental Ego States of Integrated Self (De Luca and Tosi, 2011). Crossing the two orthogonal dimensions of SASB, Affiliation (Friendly - Hostile) and Interdependence (Individuation/Give power - Enmeshment/Take away power) allows four categories of Ego states to be defined: Free, Protective, Critical and Rebellious. In each of these categories prototypes of Parent, Adult, and Child Ego States are described.

\section{Analysis}

Five studies were conducted, one for each driver, using the same sample and the same methodology. Two way ANOVA was performed with 12 Self Ego states as dependent variables. Independent variables were gender (male and females) and level of driver (1=low, $2=$ average, $3=$ high). The presence of interactions between gender and driver suggested considering the results in distinct way for men and women.

The measures of the 12 Ego States were organized in a profile that corresponds to an egogram for each group of the plan of analysis. To evaluate the integration of Self, absolute values of the 12 scales were considered, and also the whole shape of the profile, in particular assessing the relationships between the four categories 
Figure 1: Ego States in Social-Cognitive TA

\begin{tabular}{|c|c|c|c|}
\hline & & Parent Ego Stat & \\
\hline Rebellious & Free & $\begin{array}{l}\text { Free Parent } \\
\text { Protective Parent } \\
\text { Critical Parent }\end{array}$ & $\begin{array}{l}\mathrm{FC} \\
P P \\
\mathrm{CP}\end{array}$ \\
\hline Hostile & Friendly & Rebellious Parent & \\
\hline & & $\underline{\text { Adult Ego State }}$ & \\
\hline Critical & Protective & $\begin{array}{l}\text { Free Adult } \\
\text { Protective Adult } \\
\text { Critical Adult }\end{array}$ & \\
\hline Take a & ower & Rebellious Adult & \\
\hline & & Child Ego State & \\
\hline & & $\begin{array}{l}\text { Free Child } \\
\text { Protective Child } \\
\text { Critical Child }\end{array}$ & \\
\hline & & Rebellious Child & \\
\hline
\end{tabular}

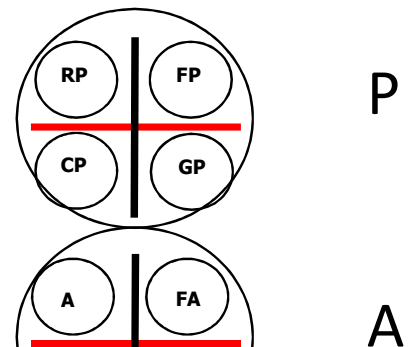

Figure 2: 12 Ego States in the circumplex

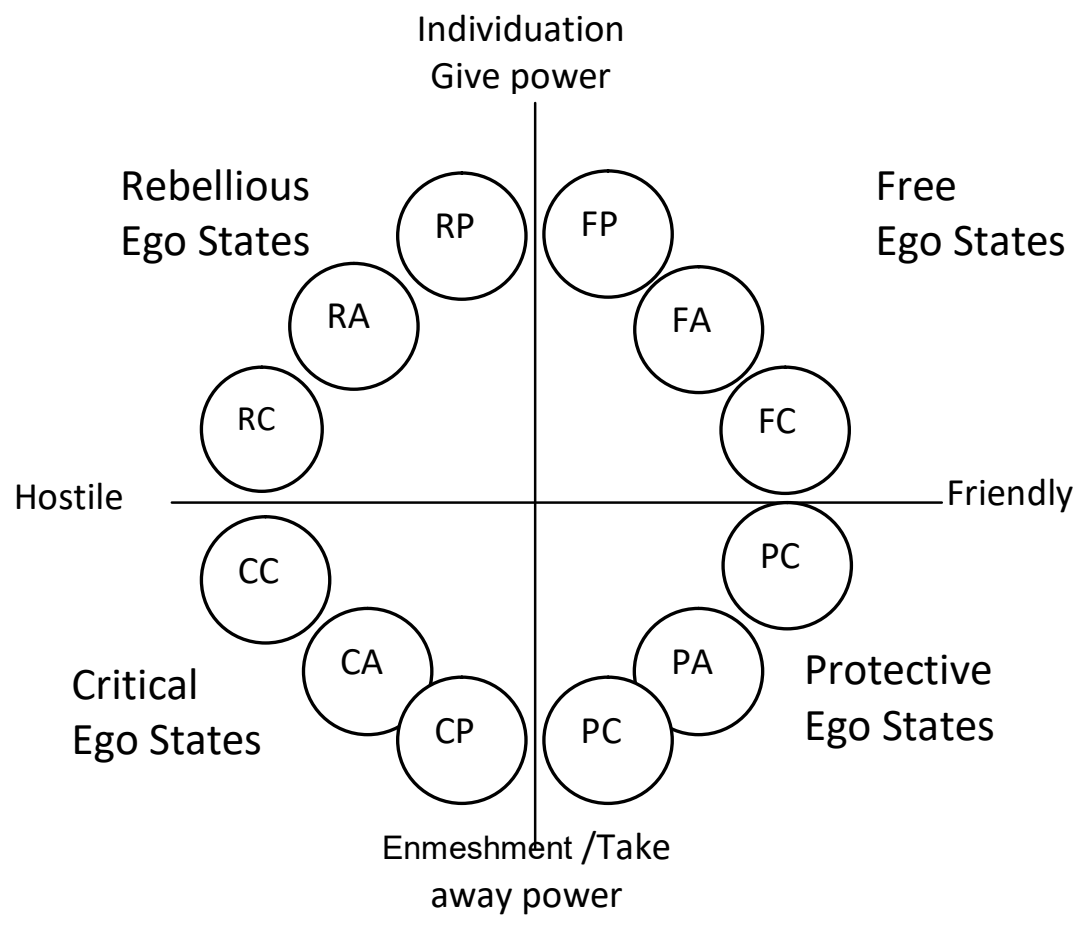


Figure 3 shows an example of a Self Ego state profile typical of wellness and suggesting a good Selfintegration. When the Self is well integrated, Free and Protective Ego states are well developed, and Critical and Rebellious Ego states are poorly developed. Free Adult (FA), Free Child (FC), Protective Child (PC), and Protective Adult (PA) are the most developed, Free Parent (FP) and Protective Parent (PP) are moderately developed. This profile suggests the activation of health processes, characterized by love toward self, together with freedom (Free Ego States) or with control (Protective Ego States). Moreover, in a good Self integration there is a balance between Free and Protective Ego states that suggest that the person can integrate in a flexible way the processes of Free and Protective Ego states. The development of Critical and Rebellious Ego states suggests the activation of dysfunctional processes characterized by hostility toward self together with control (Critical ES) or freedom (Rebellious ES). When these Ego states are very developed and/or there is an imbalance between Free and Protective ES, Self-integration is poor, wellness is limited and there is pathology of Ego states: Free, Protective, Critical and Rebellious.

\section{Results}

Means and detailed results of ANOVA can be found in the five original works.

ANOVA results of the five studies are summarized in Table 1, that shows the $p$ for the 12 Self Ego states (columns) for the factors Gender and Driver, and the Interaction between the two factors (rows). All these data are presented for each driver.

The factor Driver is related to significant difference $(p<$ .05 ) in five or more Self Ego states for every driver.

The factor Gender is related to significant difference $(p<$ .05 ) in five or more Self Ego states for four drivers and only in two Ego states for Please Me.

The interaction Gender $x$ Driver is significant $(p<.05)$ in two or more Self Ego States for four drivers, except Be Perfect (no interactions).

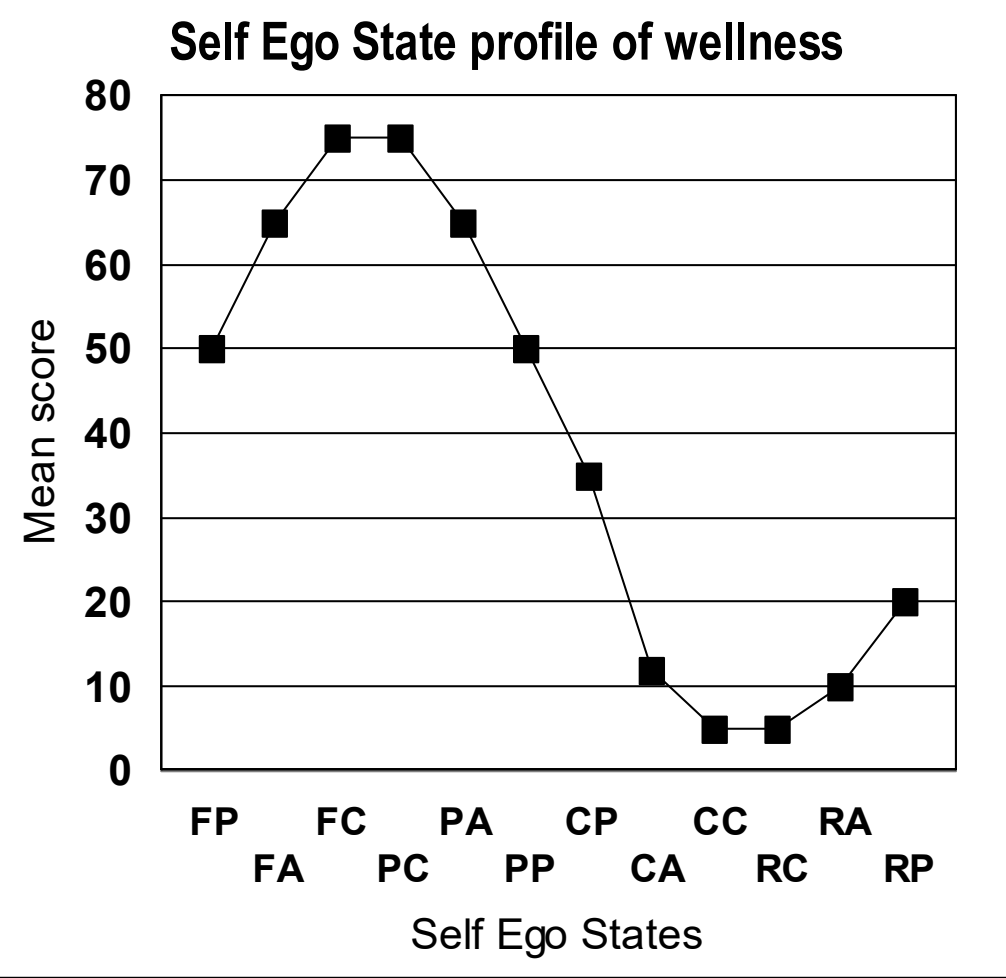


Table 1 - Summary of significant variance in factorial ANOVA from the five studies.

\begin{tabular}{|c|c|c|c|c|c|c|c|c|c|c|c|c|c|}
\hline \multirow{2}{*}{ DRIVER } & \multirow{2}{*}{$\begin{array}{l}\text { Significant } \\
\text { Variance } \\
\text { In factorial } \\
\text { ANOVA }\end{array}$} & \multicolumn{12}{|c|}{ SELF EGO STATES } \\
\hline & & FP & FA & FC & PC & PA & PP & $\mathrm{CP}$ & CA & CC & $\mathbf{R C}$ & RA & $\mathbf{R P}$ \\
\hline \multirow{3}{*}{$\begin{array}{l}\text { Hurry } \\
\text { Up }\end{array}$} & Gender & .008 & .000 & & & & .012 & & .000 & .003 & & & \\
\hline & Driver & .020 & .000 & .000 & .001 & & .000 & .002 & & & .048 & .002 & \\
\hline & Inter. GxD & .029 & .041 & & & & & & & & & & \\
\hline \multirow{3}{*}{$\begin{array}{l}\text { Please } \\
\text { Me }\end{array}$} & Gender & & & & & & & & .000 & .014 & & & \\
\hline & Driver & .000 & .000 & .000 & & & .001 & .000 & .000 & .000 & .001 & .000 & .048 \\
\hline & Inter. GxD & .005 & & & .011 & & & & & & & & \\
\hline \multirow{3}{*}{$\begin{array}{l}\text { Try } \\
\text { Hard }\end{array}$} & Gender & .015 & .001 & & & .001 & & .007 & .000 & .000 & & & \\
\hline & Driver & & & & & .000 & .000 & .000 & .016 & .000 & .015 & & \\
\hline & Inter. GxD & & .000 & .000 & .000 & & & .015 & .000 & .000 & .000 & .000 & \\
\hline \multirow{3}{*}{$\begin{array}{l}\text { Be } \\
\text { Strong }\end{array}$} & Gender & .048 & .000 & .006 & & & & & .000 & .008 & & & \\
\hline & Driver & & .002 & .004 & .000 & & .005 & .016 & & & & & \\
\hline & Inter. GxD & & .003 & .051 & & & .008 & & & & .033 & .028 & \\
\hline \multirow{3}{*}{$\begin{array}{l}\text { Be } \\
\text { Perfect }\end{array}$} & Gender & .018 & .000 & & & .023 & & .019 & .000 & .000 & & & \\
\hline & Driver & .000 & & & & & .000 & .000 & & & .028 & .008 & .000 \\
\hline & Inter. GxD & & & & & & & & & & & & \\
\hline
\end{tabular}

In color $p<0.05$ in factorial ANOVA. Ind.Var.: Gender, Driver (three levels); Dep.Var.: 12 Self Ego States

Below is a summary of the results of the five studies.

\section{Hurry Up}

Bastianelli, Centofanti e Scilligo (2004) found that average levels of Hurry Up driver (Male $M=14,59$; Females $M=14,45$ ) was associated with Self Ego state profiles in which Free and Protecting ES were well developed and Critical and Rebellious ES were low, indicating good self integration both in males and females. In general the result suggests the capacity to act quickly to maintain the competence to limit themselves and consider both self and the environment, integrating feeling and thinking.

In high levels of Hurry Up (Male $\mathrm{M}=19,11$; Females $=19,74$ ) Self Ego state profiles were similar for females and males, and showed a poor developing of Free ES, suggesting poor self-confidence and poor self contact, and high levels of Protecting Parent and Critical Parent, indicating an excess of self control, and a rise on Rebellious Child and Rebellious Adult suggesting some self neglect.

Low levels of Hurry Up (Male $M=9,89$; Females $=10,08$ ) presented profiles with high Free and Protective ES and Low Critical and Rebellious ES suggesting a good Selfintegration both for females and males. In males with low levels of the driver Free ES were more developed than in males with average levels. This result suggests that males with low levels of Hurry Up have a better self contact than males with average levels.
The hypothesis that average levels of Hurry Up are associated with a Self Ego state profile indicating good Self-integration, and the hypothesis that high and low levels of the driver are associated with dysfunctional Self Ego state profiles was partially confirmed, because not only average levels, but also low levels correlated with a good self integration.

\section{Please Me}

Guglielmotti, D'Aversa, Scilligo, and Schietroma (2004) observed that average levels of Please Me driver (Males $M=11,81$; Females $M=12,13$ ) both in females and males show an Ego states profile typical of good Self integration: high levels of Free Adult, Free Child, Protective Child and Protective Adult; low levels of Critical and Rebellious Ego states, and average levels of Free Parent and Protective Parent. This profile is related to a good capacity to be flexible, having initiative and also taking into account others.

High levels of Please Me (Males $M=15,90$; Females $M=16,58$ ) is associated with Self Ego state profile indicating poor self integration, both in males and females. In particular males were low on Free Adult and Free Child, high on Protective Parent and on Critical and Rebellious ES. This suggests poor self-acceptance and poor self-contact, and protecting strategies based on high self-control, self-criticizing and self neglect. The profile of the females was similar to that of males, and also showed a very low Free Parent and a Protective 
Child lower than men, suggesting also poor autonomy and less self love than male.

In low levels of Please Me (Males $M=8,11$; Females $M=8,57)$ Self ES profiles need a careful examination. Male profile presented low Critical and Rebellious ES, like average levels ones and high Free ES and averagehigh levels of Protective ES. In particular there is an imbalance between Free and Protective ES: Protective Adult is much lower than Free Adult, and Protective Parent is lower than Free Parent. This indicates an excess of self-confidence and poor self-control and selflimitation that may cause problems in interpersonal relations. Males with low Please Me may be too centred on self and poorly capable of adapt to others. Females with low levels of Please Me showed a profile similar to average level ones, but Critical and Rebellious Child were a little higher and Free Parent and Free Adult were higher. Free Parent was higher than Protective Parent suggesting that freedom and self-confidence exceed self-control. This result may be associated with poor flexibility in relation with other.

Results confirmed the hypothesis that average levels of Please Me are associated with a Self Ego state profile indicating good self integration, and high and low levels of the driver are associated with dysfunctional Self Ego profiles.

\section{Try Hard}

D'Aversa, Caizzi, and Scilligo (2004) found that average levels of Try Hard driver (Males $M=16,72$; Females $M=16,24$ ) were associated with Self Ego state profiles in which Free and Protecting ES where well developed and Critical and Rebellious ES were low, indicating good self integration both in males and females. This result suggests that subjects are capable of activating protective strategies where they put energy in a balanced way into giving self direction and respecting themselves.

High levels of Try Hard (Males $M=21,37$; Females $M=21,51$ ) presented dysfunctional Self Ego states profiles in males and females, with different characteristics in the genders. Males showed very high Free Adult, Free Child, Protective Ego states, and Critical Parent, suggesting too much self-confidence and too much self control. Females showed low Free Ego states and high Critical and Rebellious Ego states, indicating poor self confidence, too much self control and auto criticism, hostility toward self and self neglect.

Low levels of Try Hard (Males $M=11,68$; Females $M=11,64)$ showed Self Ego states profiles with dysfunctional aspects, mostly for males, that had low Free Adult, Free Child, and Protective Ego states, suggesting poor self confidence, poor self love and poor self protection. Females had a profile similar to that of average levels, but Protective Adult and Parent were also low, indicating poor self-protection and poor selfcontrol.

Results confirmed the hypothesis that average levels of Try Hard are associated with a Self Ego state profile indicating good self-integration, and high and low levels of the driver are associated with dysfunctional Self Ego profiles.

\section{Be Strong}

Bove, D'Aversa, Scilligo, and Carpineto (2004) found that average levels of $\mathrm{Be}$ Strong (Males $\mathrm{M}=13,26$; Females $M=12,48$ ) were associated with a Self Ego state profile typical of good integration in females and males. Critical and Rebellious ES were low, Free and Protecting ES were well developed and balanced indicating a good self confidence and contact with self combined with good self protection. This suggests the capacity to manage emotions and to use their resources to cope with difficulties, without losing the ability to listen and to ask for help if necessary. High levels of Be Stong (Males $M=17,17$; Females $M=16,65$ ) is associated with very different profiles for males and females. Males presented a Self Ego state profile very similar to average level ones. Only Protective Child is a bit lower. This indicates a good integration of Self for males with high levels of Be Strong, even if these subjects may have a lack of tenderness toward themselves. In Females all the Free ES and Protective Child were also low, indicating poor self-confidence, poor contact with self, and poor self-love. Critical Parent was high, indicating a strong self-control, and Rebellious ES were higher than the other two groups suggesting some self-neglect.

Also for low levels of Be Strong (Males $M=9,45$; Females $M=8,76)$ Self Ego states profiles were different in the genders. Males with low Be Strong presented Free Ego state similar to average and high-level ones. Also, Critical Adult and Child, and Rebellious Adult and Parent were similar to other groups. Nevertheless Protective Child, Protective Parent and Critical Parent were noticeably more elevated than in the other two groups. This indicates an excess of self-protection and selfcontrol that may indicate limitation in exploration and sense of vulnerability. Also Rebellious Child was more elevated and suggests some hostility toward self. Females with low Be Strong, different to males, have a Self ES profile just similar to average level one. Thus for females a low Be Strong corresponds to a healthy condition.

Results partially confirmed the hypothesis that average levels of Be Strong are associated with a Self Ego state profile indicating good self-integration, and high and low levels of the driver are associated with dysfunctional Self Ego profiles. In fact subjects with average levels of Be Strong had profiles indicating good integration, but low Be Strong results were associated with poor selfintegration only in males, and high Be Strong was associated with poor self-integration only in females.

\section{Be Perfect}

Caizzi, Bove and Scilligo (2004) found that average levels of Be Perfect (Males $M=16,47$; Females $M=16,54$ ) were associated with a Self Ego state profile typical of good integration in females and males. This result suggests that subjects with average levels of Be Perfect have the capacity to do things well and look for precision, keeping a friendly attitude toward self and a balance between give freedom to self and self control. 
High levels of Be Perfect (Males $M=19,97$; Females $M=19,74$ ) showed different profiles in males and females. Males had a Self Ego state profile very similar to average level males. They presented only a little more elevated Protective Parent and Critical Parent in comparison with other groups of males, indicating higher self control, however the profile suggests a good integration of self. In contrast, females showed a profile with low Free Ego states and high Protective Parent and Critical Parent, suggesting poor self-confidence, poor self-acceptance, and also self-control.

Low levels of Be Perfect (Males $M=13,16$; Females $M=13,45$ ) presented some dysfunctional aspect with differences for males and females. Males had Free Adult, Free Child, Protective Child, and Protective Adult a little low, and Rebellious Ego states were elevated. This result suggests too self-neglect. Females with low levels of Be Perfect showed a profile similar to the ones with average levels of driver, but presented an imbalance between Free Parent (too high) and Protective Parent (too low). This result suggests a little deficit in friendly self-control.

Results partially confirmed the hypothesis that average levels of Be Perfect are associated with a Self Ego state profile indicating good self-integration, and high and low levels of the driver are associated with dysfunctional Self Ego profiles. Subjects with average levels of Be Perfect had profiles indicating good integration, the ones with low levels of Be Perfect had less self integration, but high Be Perfect results were associated to less self integration only in females.

The results largely confirmed the hypothesis of a curvilinear relation between levels of drivers and integration of the Self. The results suggest that average levels of drivers are adaptive because they are associated with profiles of Ego States indicating well being and integration of the Self. The part of the hypothesis which states that high levels of drivers are dysfunctional, found support for all drivers except for Be Perfect and Be Strong, where high levels in men are associated with profiles showing good integration of the Self. The part of the hypothesis that even low levels of drivers are dysfunctional has been confirmed for Please Me, Try Hard, Be Perfect, Be Strong (only for women), and was not confirmed for Hurry Up.

In summary Please Me and Try Hard showed an inverted curvilinear $U$ relationship between the levels of driver and the integration of the Self. A similar relationship emerged for Be Strong and Be Perfect, even though it seems that the gender factor can act as a moderator in the relationship between levels of driver and integration of the Self. Therefore driver levels that are adaptive for males may not be adaptive for females, and vice versa. For Hurry Up driver the curvilinear relation is not confirmed because only high levels of Hurry Up are associated with dysfunctional processes in the Self.

Further studies may clarify the relationship between drivers and integration of the self, considering the latter variable also from other perspectives, using measures other then self-evaluation questionnaires, and different clinical samples.

\section{Conclusions}

Research like this help us to verify the validity of the theoretical constructs of Transactional Analysis. In this case it largely confirmed the hypothesis of a curvilinear relation between drivers and integration of the Self. The results show that drivers can be protective and adaptive strategies if implemented at moderate levels, and tend to be associated with problematic conditions when they are low or high. We want to emphasize that the hypothesis is consistent with OKness and its empirical test helps us to remove from the concept of drive the "Not OK" connotation assumed over the course of time. Research results urge us to reflect on what attitude to adopt about drivers in therapeutic and educational contexts in order to recognize both maladaptive and adaptive aspects, giving empirical support to TA Authors mentioned in this article (Kahler, Clarkson, Hazell, Conway, Caper and Goodman, Mescavage, Silver, Gellert, Johnson).

In addition, these studies allow us to enrich the knowledge of Anint and Espero which are used not only in research but also in clinical practice. The Anint focuses on a more abstract level of analysis, giving information on the interpersonal dimension of ego states, and the Espero investigates at a lower level of abstraction the protective strategies of activation and inhibition, which in TA are called drivers and injunctions, helping us to get script contents related to the ego states. Therefore, by correlating the results of these instruments we can enrich meanings of the data we get from them.

\section{References}

Bastianelli, L., Centofanti, S., Scilligo, P., (2004). La controingiunzione Spicciati e gli Stati dell'lo Sè. La controingiunzione Spicciati e gli Stati dell'lo Sè. Psicologia Psicoterapia e Salute, 10, 39-50

Bastianelli, L., D’Aversa, C., Scilligo, P., (2004) Psicologia Psicoterapia e Salute, 10, 21-37.

Benjamin, L.S. (1974). Structural analysis of social behavior (SASB). Psychological Review, 81, 392-425.

Benjamin, L. S. (1996). Interpersonal theory of personality disorders. In J. F. Clarkin and M. F. Lenzenveger (Eds.) Theories of Personality Disorders. New York: Guilford Press.

Benjamin, L. S. (2000). Intrex user's manual. Salt Lake City: University of Utah.

Benjamin, L. S. (2003). Interpersonal Reconstructive Therapy. Promoting change in non-responders. New York: Guilford Press.

Berne, E. (1968). A layman's guide to psychiatry and psychoanalysis. New York: Simon and Shuster.

Berne, E. (1970). Sex in Human Loving. New York: Simon \& Schuster.

Bove, S., D’Aversa, C., Scilligo, P., Carpineto, L. (2004) La controingiunzione Sii Forte e gli Stati dell'lo Sè. Psicologia Psicoterapia e Salute, 10, 75-84. 
Caizzi, C., Bove, S., Scilligo, P., (2004) La controingiunzione Sii Perfetto e gli Stati dell' lo Sè. Psicologia Psicoterapia e Salute, 10, 85-94

Ceridono, D., Gubinelli, M., Scilligo, P. (2009). Gli Stati dell'lo nell'Analisi Transazionale Socio-Cognitiva: la definizione dimensionale. Idee in Psicoterapia, 2, N², 85-100.

Clarkson, P. (1992). In praise of speed, experimentation, agreeableness, endurance, and excellence: counterscript drivers and aspiration. Transactional Analysis Journal, 22, 1620.

Conway, N. V. (1978). Drivers and dying. Transactional Analysis Journal, 8, 345-348.

D’Aversa, C., Caizzi, C., Scilligo, P., (2004) La controingiunzione Dacci Dentro e gli Stati dell'lo Sè. Psicologia Psicoterapia e Salute, 10, 61-74.

De Luca, M.L., Tosi , M.T. (2012). Social-Cognitive Transactional Analysis : An introdution to Pio Scilligo's model of Ego states. Transactional Analysis Journal, 41, No 3, 206-220.

Gellert, S. D. (1975). Drivers. Transactional Analysis Journal, 5 422-428.

Goulding, R. L., Goulding McClure, M. (1979). // cambiamento di vita nella terapia ridecisionale. Roma: Astrolabio.

Guglielmotti, F., D’Aversa, C., Scilligo, P., Schietroma, S. (2004) La controingiunzione Compiaci e gli Stati dell'lo Sè. Psicologia Psicoterapia e Salute, 10, 49-60.

Hazell, J. W. (1989). Drivers as Mediators of stress response. Transactional Analysis Journal, 19, 212-223.

Johnson, D. (1997). Working styles: the application of the concept of Drivers to owner-managers of small Businesses. Transactional Analysis Journal, 27, 65-75.
Kahler, T. \& Capers, H (1974). The Miniscript. Transactional Analysis Journal, 4, 26-42.

Kahler, T. (1975). Scripts: Process and Content. Transactional Analysis Journal, 5, 277-279.

Kahler, T. (1975). Drivers: the key to the process of scripts. Transactional Analysis Journal, 5, 280-284.

Mescavage, A., Silver, C. (1977). "Try Hard» and "Please Me» in psychological development. Transactional Analysis Journal, 7, 331-334.

Scilligo, P. (2000). II questionario ANINT-A36: uno strumento per misurare la percezione di sé. Psicologia Psicoterapia e Salute, 6, 1-35.

Scilligo, P. (2003). Defining Ego States in relational and developmental terms. EATA Newsletter, n. 79, February 2004, 7-13.

Scilligo, P. (2005). La nuova sinfonia dei molti Sé. Roma: LAS.

Scilligo, P. (2009). Analisi Transazionale Socio Cognitiva. Roma: LAS.

Scilligo, P., and Benjamin, L. S. (1993). L'analisi strutturale del comportamento interpersonale. In Scilligo, P. (a cura di), Sistemi intrapsichici e interpersonali. Roma: IRPIR.

Scilligo, P., \& De Luca, M. L. (1997). Copione del terapeuta e alleanza terapeutica. Psicologia Psicoterapia e Salute, 3, 1-20.

Scilligo, P., D'Aversa, C., Liverano, A., Schietroma, S., Guglielmotti, F., Miletta, C., Flora, C. (1999). II questionaro ESPERO: la misurazione delle ingiunzioni e delle controingiunzioni. Psicologia Psicoterapia e Salute, 5:, 137-164. 